\title{
Entrepreneurship in Microscopy: Identifying and Addressing Needs in the Microscopy Market
}

\author{
Daniel Masiel $^{1}$ \\ 1. Integrated Dynamic Electron Solutions, Inc., Pleasanton, California USA \\ * Corresponding author: dan@ides-inc.com
}

Microscopy, like many other fields in contemporary science, is supported by a thriving commercial sector that includes a wide variety of companies serving an equally diverse set of market needs. The Microscopy and Microanalysis 2019 conference and exhibition includes businesses ranging from large, publicly traded equipment manufacturers to single-person consultancies. These diverse companies have all thrived by being able to provide products or services that their customers demand. Finding a repeatable, sustainable way to deliver the right solutions that address relevant customer needs is the fundamental challenge of entrepreneurship.

In this session, founders, innovators, and business leaders from the microscopy community and beyond share their experiences and perspectives on entrepreneurship and the process of starting a business. Panelists will each give a brief presentation on their background, their business, and their thoughts on our topic: "Identifying and Addressing Needs in the Microscopy Market". The session will conclude with Q\&A.

Panelists will focus on the role of the end user's needs as a driver of business, innovation, and technology. They will address common pitfalls of entrepreneurship, such as creating a business based on a "solution looking for a problem" and will discuss the role of strategic marketing in ensuring that this doesn't happen. By undertaking a systematic process to understanding customers' needs and motivations, a business can deliver a product with a better market fit. However, not all strategic marketing strategies are effective or appropriate in the microscopy market, and this session will explore the particular nuances of the field.

Additionally, panelists will answer the following questions relevant to product development and first time entrepreneurship:

- How do I identify and asses the market need for what I'm considering?

- How do I quantify the opportunity this need represents?

- Where can I find more information and data to test my assumptions?

- How do I build a business that addresses this need?

- I've done all of this research, what now?

Attendees will leave this tutorial with useful insights into how entrepreneurs and innovators in the microscopy industry address these questions and think about strategic marketing in their own endeavors.

Like many startups in the microscopy community, Integrated Dynamic Electron Solutions (IDES) began in a research lab. While the lab environment is great for developing new and exciting technologies, the IDES team had to look elsewhere to find to people with fresh perspectives on the utility of those 
technologies. The IDES team spent ample time talking to customers before developing its first commercial Luminary system. Continued customer research and data gathering provided the inputs to the development roadmap and new product features. Figure 1 below shows a comparison between IDES' first Luminary systems to one of its most recent installations.
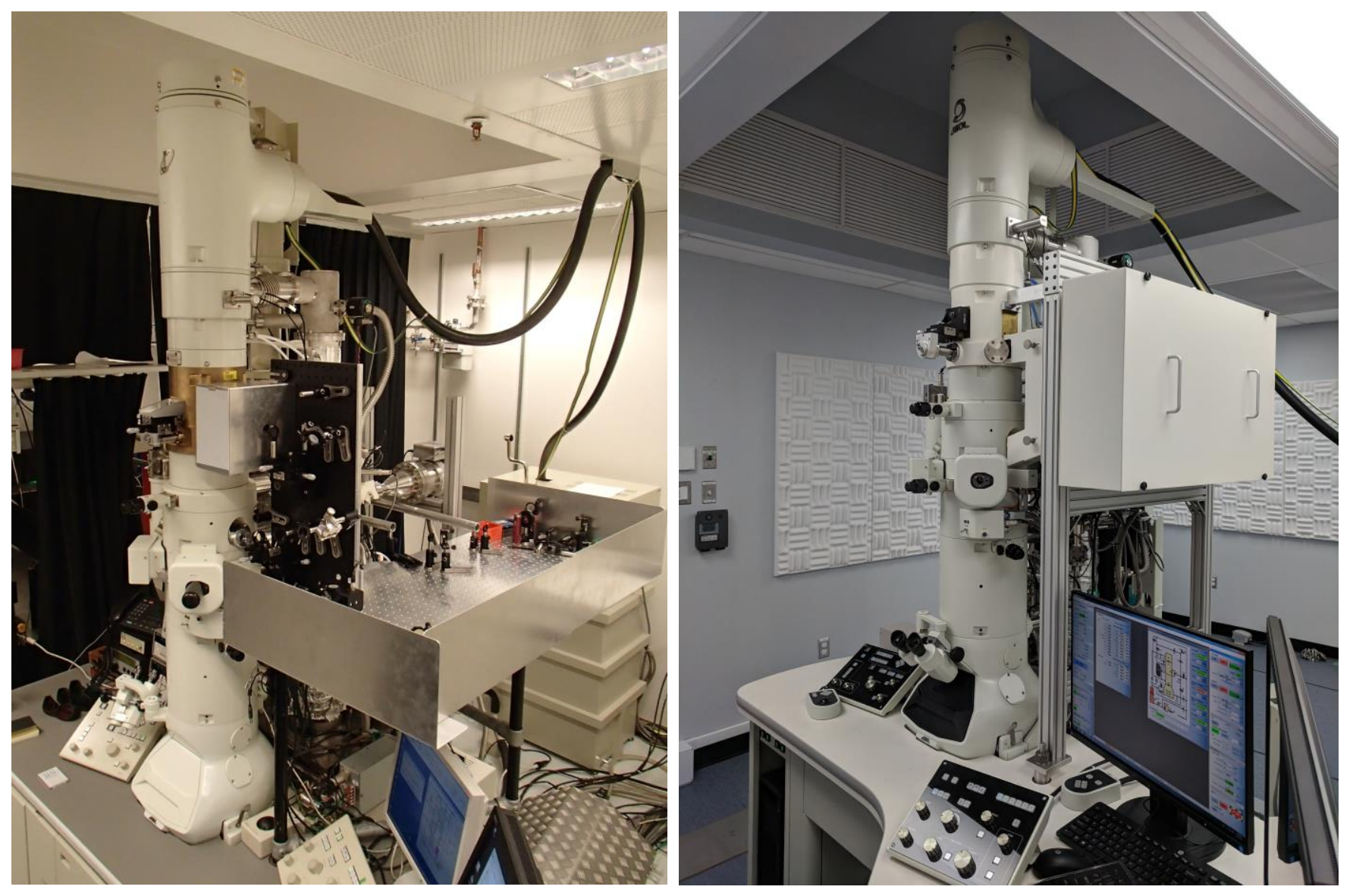

Figure 1. IDES first Luminary system (left, 2013) compared to one of its most recent (right, 2018). 